\title{
Enhancing Students' Learning of Physics Concepts with Simulation as an Instructional ICT Tool
}

\author{
Elizabeth Darko Agyei ${ }^{1 *}$ (D), Douglas Darko Agyei ${ }^{1}$ (i)
}

${ }^{1}$ University of Cape Coast, GHANA

*Corresponding Author: elizabeth.cornah@ucc.edu.gh

Citation: Agyei, E. D., \& Agyei, D. D. (2021). Enhancing Students' Learning of Physics Concepts with Simulation as an Instructional ICT Tool. European Journal of Interactive Multimedia and Education, 2(2), e02111. https://doi.org/10.30935/ejimed/11259

\begin{abstract}
The dwindling interest and perceived difficulty experienced by science students in learning physics at the senior high school level of education in Ghana speak to the need for the creation of authentic instructional platforms that promote enhanced learning as well as motivate students' interest in physics. This study used an explanatory case study design to examine the affordances of Physics Education Technology simulations (PhETs) as an instructional tool with the intent to explain how enhanced students' learning of physics concepts with simulations through implementation processes are possible in the context of Ghana. Nine pre-service physics teachers were engaged as learners to mimic the role of senior high school science students in witnessing simulation-based physics lessons. Questionnaires, pre- and post-tests and focus group interviews were the data sources employed in this study. The results showed that the learners' learning enhanced with the use of PhETs because their learning outcomes improved and also, they had positive experiences with the simulations. Consequently, the study advocates that enhanced learning of concepts in physics with simulations are possible through interactive implementation processes that are exploratory and demonstrative in nature and context-sensitive.
\end{abstract}

Keywords: high school physics, ICT, students' learning, simulations-supported lessons

Received: 21 May. $2021 \bullet$ Accepted: 17 Aug. 2021

\section{INTRODUCTION}

Physics as a subject, though described as a fundamental science in general, is mostly perceived to be a difficult and non-interesting science especially, at the high school level of education not only in Ghana, but internationally. There are several reasons to this perception. These may include students' personal understanding of physics (Gray et al., 2008); the method of instruction being used in teaching the subject (Azure, 2015; Buabeng et al., 2012; Donnellan, 2003); and to a large extent, the mathematics required for solving problems in physics (Taale, 2011). Behar and Polat (2007) also added misconception as a contributing factor to the difficulty of certain physics topics which could result from students' personal experiences (Martin et al., 2002). These prevalent issues call for efficient ways of teaching physics (Thompson \& Logue, 2006) and hence, seem to echo the need for relevant and suitable teaching methods and technology-based interventions to be adopted for the purpose of not just clearing students' misconceptions about physics, but also, providing authentic avenues for enhanced learning of the subject matter. Literature highlight the potentials of information and communication technology (ICT) (e.g., simulations) among others to facilitate conceptual change (Chatzopoulos et al., 2021; Finkelstein et al., 2005; Stieff, 2003; Zacharia \& Anderson, 2003; Zacharia, 2007), enable students to be authentic in achieving their personal goals, develop critical thinking skills, construct their own knowledge, develop content knowledge (Bell \& Smetana, 2008; Fan et al., 2018), and to actively interact with teaching and learning materials (Allan, 2007; Fu, 2013; Koh, 2013; Mbodila et al., 2013). However, most of the literature mentioned herein examined the potentials of computer simulations in relation to how they had been used in the developed countries to facilitate the teaching and learning of physics concepts. This seems to suggest that existing literature has not explored adequately the potentials of simulations from the perspective of the less developed countries like Ghana among others, even though such an initiative, when undertaken, has the tendency to provide the developers of various existing science content-specific simulation environments with valuable insights for upgrading their respective simulation interfaces to be more context-friendly for effective integration into physics instruction world-wide. That notwithstanding, the aforementioned potentials of simulations to a large extent, seem not to have been exhausted at all in Ghanaian physics classrooms at the senior high school level; as teachers are not using ICT in their teaching practices (Agyei \& Agyei, 2019). In light of these gaps, the present study, through implementation processes, explored the affordances of Physics Education Technology simulations (PhETs), which are developed on research basis at the University of Colorado, Boulder (http://phet.colorado.edu), as an instructional ICT tool with the intent to provide an account of how enhanced students' learning of physics concepts are possible in the context of Ghana. Consequently, the study 
sought to address the question: How can enhanced students' learning of physics concepts using simulations be understood and/or explained?

\section{LITERATURE REVIEW}

The potentials of simulations use in the physics classroom have been explored and studied in different contexts in relation to different physics concepts in literature (Dega et al., 2013; Jimoyiannis \& Kosmis, 2001). For example, Jimoyiannis and Kosmis (2001) used computer simulations to foster students' understanding of physics concepts such as velocity and acceleration in projectile motion. Findings of their work, as explained in Esquembre (2001) showed that by the use of simulations, students were provided with the conducive environment to: a) "develop their understanding about the phenomena and physical laws through a process of hypothesis-making and idea-testing”; b) “... develop an understanding of the relationships between physical concepts, variables and phenomena"; C) "employ a variety of representations (images, animations, graphs, numerical data) that are helpful in understanding the underlying concepts, relations and processes"; and d) "investigate phenomena that would not be possible to experience in a classroom or laboratory" (Esquembre, 2001, p. 4). According to Jimoyiannis and Kosmis (2001), the use of simulations helped the students to get better understanding of the physics concept which reflected in the high scores they obtained in the tasks given them. These findings seem to emphasize the potential of computer simulations in provoking students' knowledge construction of concepts in physics based on their experiences with various simulation environments. Trundle and Bell (2005) compared students' conceptual understanding before and after an instruction on lunar concepts mediated by planetarium simulations. Their findings showed that the affordances of simulations (i.e., in making more observations, allowing predictions to be explored, taking consistent and accurate measurements) were essential to the enhancements in students' understanding of the lunar concept, as it allowed them to observe the moon phases which in reality, seemed impossible to observe. This brings out the potential of simulations as a visualizing tool. This seems to align with Kohnle (2014)'s assertion that with simulations, students are able to visualize invisible abstract concepts as well as observe microscopic processes. Dega et al. (2013) also used computer simulations to examine gains in students' conceptual understanding of electricity and magnetism. Findings revealed that additional instructional support was key to improvements observed in students' understanding of the concepts investigated. Other benefits of computer simulations in relation to physics learning include "improving the teaching/learning process based on conceptual understanding” (El Kharki et al., 2020, p. 131; Pucholt, 2021), promoting interactivity in the physics classroom (Agyei et al., 2019), enhancing students' performance in learning physics (Ouahi et al., 2021) and affording students the space to explore a wide range of topics in physics through its multiple representation feature (Fan et al., 2018; Nadiradze et al., 2020; Podolefsky et al., 2010). These seem to reflect the potentials of PhET simulations, in that, they are designed to provide interactive platforms that engage students to learn through exploration and discovery with the goal to help students to connect real-life phenomena to the underlying subject matter in a particular science (Finkelstein et al., 2006; Wieman et al., 2010). The dynamic feedback feature of PhETs is also designed to provide direct feedback to students as they interact with the simulation environment. According to Clark and Mayer (2003), such a feature is essential for developing students' conceptual understanding as well as the relationships that exist among the concepts under exploration. PhETs are also noted for their capacities to "support student engagement ... and understanding of physics concepts". The affordances of PhETs as mentioned in the literature herein, seem to situate the PhETs as "highly effective learning tools" (Wieman et al., 2010, p. 225) and hence, the reason for its use in the context of this study.

\section{RESEARCH METHODOLOGY}

\section{Research Design}

This study employed an explanatory case study design of nine preservice teachers to explain the extent to which the potentials of simulations when explored through instructional processes, enhance students' learning of concepts in physics. Both qualitative (e.g., focus group interview and written responses on pre- and post-test documents) and quantitative (e.g., pre-and post-test scores and survey) evidence of data collection and analysis were employed for triangulation purposes. We emphasis here that the use of quantitative evidence in this study was not intended for making statistical generalization, but rather to help strengthen the veracity of any explanation given in relation to the phenomenon being considered (Yin, 2003). Data were collected over a stretch period of seven weeks. This was however, subjected to the convenient times of the participants.

\section{Participants}

Nine pre-service physics teachers participated in the study as the unit of analysis. These were in their second year of the science teacher education programme at the University of Cape Coast (UCC) Ghana. A purposive sampling method was used in the selection of the participants. This was subjected to the "researchers' experience and knowledge" of the pre-service teachers (Kothari, 2004) based on their seriousness and commitment. The participants witnessed the enactment of two sets of simulation-supported physics lessons (SSPLs) on the topics: Deformation of Solids (DOS) and Frictional Force (FF). During the implementation of the SSPLs, the participants were engaged as learners to mimic the role of senior high school science students, thus, the term 'learners' from this point forward, refers to the participants. It is important to mention that the participants had never experienced the teaching of physics with simulations before, thus, the study provided an authentic avenue for them to learn physics with ICT.

The anonymity of the nine participants is protected by use of pseudonyms such as 'Learner 1', 'Learner 2' and so on.

\section{Overview of Simulation-Supported Lessons Enacted}

Two lessons on the topics: Deformation of Solids(DOS) and Frictional Force (FF) were designed and enacted in study. The lesson on $F F$ was designed to be exploratory and self-directed in delivery with emphasis on a Ghanaian classroom situation where both the teacher and students (learners) have access to the computer. The DOS lesson adopted a demonstrative mode of delivery and was designed to fit into a classroom context wherein only the teacher had access to a computer due to lack of computer resources. All two modes of delivery were purposed to be interactive and learner-focused. In particular, these lessons were developed and taught by a group of pre-service teachers who had been trained by the researchers of this study through a professional development programme on ICT integration; where they were 
Table 1. Summary of lessons designed and enacted

\begin{tabular}{|c|c|c|c|}
\hline Lesson (topics) enacted & Facilitator & Name of selected PhETs used & Mode of delivery \\
\hline Deformation of Solids & Teacher A & $\begin{array}{l}\text { Hooke's Law } \\
\text { (https://phet.colorado.edu/en/simulation/hookes-law) }\end{array}$ & Demonstrative \\
\hline Frictional Force & Teacher B & $\begin{array}{l}\text { Force and Motion: Basics (Friction) } \\
\text { (https://phet.colorado.edu/en/simulation/forces-and-motion-basics) }\end{array}$ & Exploratory \\
\hline
\end{tabular}

Table 2. Sample question for each subscale from questionnaire

\begin{tabular}{cc}
\hline Subscales & Sample questions on learners' experiences with the lessons \\
\hline Interest & Enjoyed the class and I wish such teaching with simulation will continue. \\
\hline Comprehension & The lesson explained concepts that I found difficult to understand before. \\
\hline Presentation & The content of the lesson was well delivered. \\
\hline
\end{tabular}

equipped with ICT-oriented competencies needed for the effective design, development and implementation of an ICT (simulation)-supported physics lesson. These were in their third year of the same science education teacher preparation programme at UCC. It is important to mention that, the role of this group of pre-service teachers (two in all, namely, Teacher A and Teacher B) in the context of the study was to enact the SSPLs (Teacher A enacted the lesson on $D O S$ and then teacher enacted the lesson on $F F$ ) and also, design the preand post-tests for their respective lessons. Table 1 gives a summary of lessons that were witnessed by the learners.

\section{Instrument and Procedures}

\section{Pre- and post-test}

Data were collected by use of pre- and post- tests. The tests consisted of the same items on the topics: Deformation of Solids and Frictional Force and was aimed at exploring the students' conceptual understanding of the selected topics. Both the pre-and post-tests were made up of five (5) items each for each of the topics. These tests were reviewed (by the researchers) and then, conducted before and immediately after each of the two lessons was implemented. The written responses as provided on the pre- and post-test document by the learners who witnessed the lessons were also used as a qualitative evidence in the study. A coding scheme was developed according to the extent to which respondents were able to vividly provide a solution, offer an acceptable explanation, solve, or explain the problem. The responses to the test items were scored dichotomously as either right (a score of 1 ) or wrong (a score of 0 ). Thus, the maximum score that could be obtained for each of the test was 5 . The interrater reliability (Cohen's $\kappa)$ assessed by two raters was $\kappa=0.94$. Table 3 gives an overview of the results of the pre-and post-test scores of the learners.

\section{Focus group interview}

Focus group interview was also used to collect data. This was done twice; first, after the DOS lesson and then, after the FF lesson was implemented. Discussions in this respect were purposed to ascertain the usefulness of the simulation-supported lessons in enhancing learners' understanding of concepts in physics as well as their learning outcomes. The focused group discussions were transcribed and coded using the following coding schemes: appropriateness of the simulations (AS) for learning the selected topic, use of simulation in clearing misconceptions $(C M)$, use of simulation in stimulating interest $(S I)$ of learners and the use of simulations in improving learning (IL). Two raters coded the data; The interrater reliability (Cohen's $\kappa$ ) was $\kappa=0.92$.
Survey

A questionnaire on learners' experiences with the SSPLs was used to gain insights into how the implemented lessons facilitated and enhanced learners' understanding of the two physics concepts taught. The questionnaire was designed to include items adapted from Agyei (2012). In all, 14 items were constructed and used for this purpose. Possible answers on an item were on a five-point Likert scale ( 1 =strongly disagree, 5 = strongly agree). The scores are interpreted as follows: 1 is the lowest possible score, which represents a very strong negative opinion, while the 5 is the highest possible score which represents a very strong positive opinion. The items were predetermined and grouped into three sub-scales about the learners experiences in relation to their understanding of the SSPLs (see Table 2 for sample question for each subscale). The sub-scales were: 1) Interest (Cronbach alpha $=0.87)$-this was aimed at finding out if the lessons engaged the learners' attention; 2) Comprehension (Cronbach alpha $=0.79)$ - this was used to determine how clear and understanding the lessons were; and 3) Presentation (Cronbach alpha=0.82) -this was used to determine whether the content was well explained during the delivery of the simulation-supported lessons.

The questionnaire was administered twice to the learners after the implementation of the DOS lesson and also, after the implementation of the FF lesson.

\section{DATA ANALYSIS}

To analyze the data, descriptive statistics and non-parametric statistics (Wilcoxon signed rank test) were used for the survey and the pre-and post-test scores. Effect size was calculated using Cohen's d (Cohen, 1988). Cohen (1988) provided tentative benchmarks for the interpretation of effect sizes. He considers $d=0.2$ a small, $d=0.5$ a medium and $\mathrm{d}=0.8$ a large effect size. Focus group interview data were analyzed qualitatively using data reduction techniques in which major themes were identified and clustered (Miles \& Huberman, 1994).

Document analysis was employed to analyze and give meanings to the learners' written responses to items on the pre-and post-tests document.

\section{RESULTS}

To address the research question: "How can enhanced students' learning of physics concepts using simulations be understood and/or explained", both qualitative and quantitative evidence were used. These 
Table 3. Related-Samples Wilcoxon test results for pre- and post-test mean scores (N=9)

\begin{tabular}{|c|c|c|c|c|c|}
\hline \multicolumn{2}{|c|}{ Topic } & Mean (SD) & $\mathbf{Z}$ & $\mathbf{P}$ & Effect size \\
\hline \multirow{2}{*}{ Deformation of Solids } & Pre -test & $2.67(0.500)$ & \multirow{2}{*}{-2.45} & \multirow{2}{*}{$0.014^{* *}$} & \multirow{2}{*}{0.83} \\
\hline & Post-test & $3.33(1.000)$ & & & \\
\hline \multirow{2}{*}{ Frictional Force } & Pre- test & $3.33(0.500)$ & \multirow{2}{*}{-2.45} & \multirow{2}{*}{$0.014^{* *}$} & \multirow{2}{*}{1.90} \\
\hline & Post-test & $4.00(0.001)$ & & & \\
\hline \multirow{2}{*}{ Combined (Topics) } & Pre-test & $3.00(0.594)$ & \multirow{2}{*}{-3.46} & \multirow{2}{*}{$0.001^{*}$} & \multirow{2}{*}{0.98} \\
\hline & Post-test & $3.67(0.767)$ & & & \\
\hline
\end{tabular}

${ }^{*}=p<.01{ }^{* *}=p<.05$

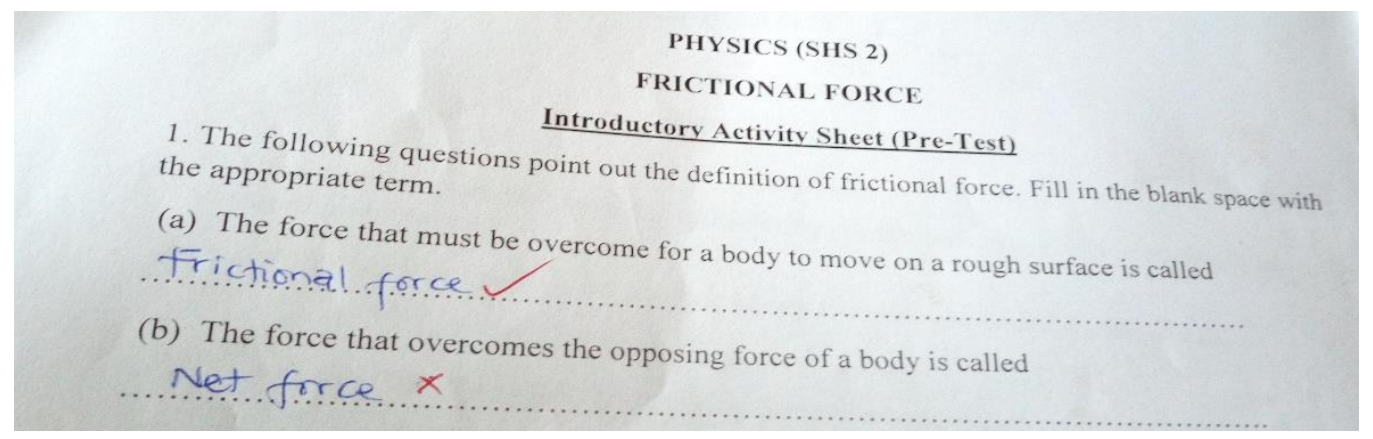

(a)

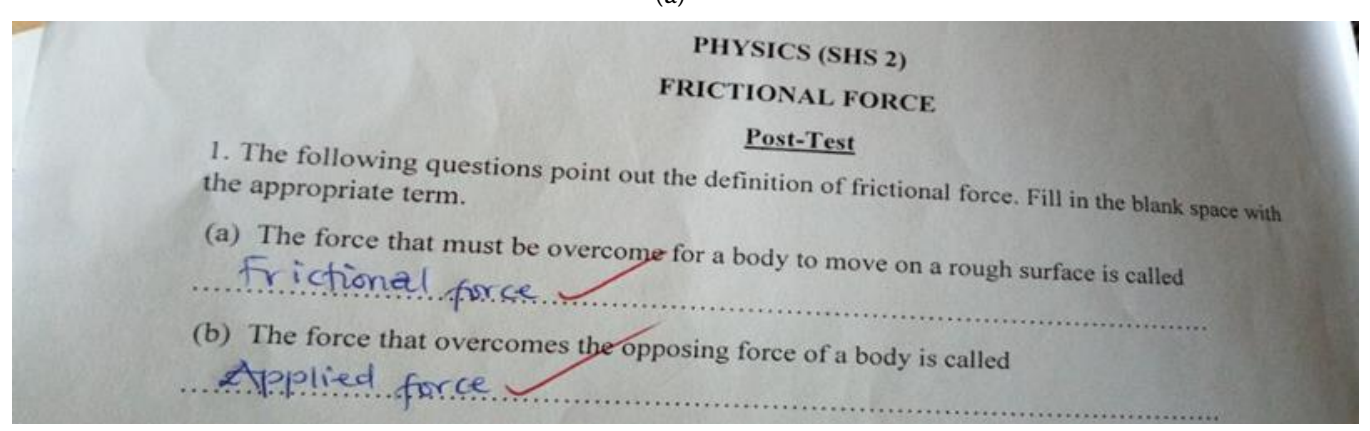

(b)

Figure 1. (a) Excerpt of Learner 3's responses to pre-test item number 1(b) before the enactment of the SSPL on Frictional Force; (b) Excerpt of Learner 3's responses to the post-test item number 1(b) after the enactment of the SSPL on Frictional Force

helped to explain the enhanced students' learning of the subject matter at two levels: improved students' learning outcomes and learners' perceived positive experiences with the SSPLs.

\section{Improved Students' Learning Outcomes}

The results of the study showed that the participants' (learners') learning of concepts in physics enhanced with the PhET simulations as their learning outcomes were found to have improved. Data from preand post-test scores, learners' written responses to items on the pre-and post-tests document as well as the focus group interview supported these results. Table 3 gives an overview of the results of the pre-and post-test scores of the learners. Table 3 seems to suggest that the test scores for the lesson on Deformation of Solids ( $p r e=2.67$, post $=3.33$ ) were lower compared to that on Frictional Force (pre=3.33, post=4.00).

A possible reason which explains the relatively low scores for the lesson on DOS could have been the difficulty level of the subject matter. That notwithstanding, it was important to ascertain whether the differences existing between the pre-post tests were significant or not.

Results from the Wilcoxon paired sampled rank test showed that there were significant differences in learning outcomes of students for both lessons: Deformation of Solids $(\mathrm{z}=-2.45, \mathrm{p}<.05)$; and Frictional Force $(\mathrm{z}=-2.45, \mathrm{p}<.05)$ with large effect sizes of $\mathrm{d}=0.83$ and $\mathrm{d}=1.90$ respectively. The overall test scores: pre $(\mathrm{M}=3.00, \mathrm{SD}=0.594)$ and post
( $\mathrm{M}=3.67, \mathrm{SD}=0.767)$ of the combined lessons also showed significant difference $(\mathrm{p}<0.01)$ with a large effect size $(\mathrm{d}=0.98)$; an indication that the PhET simulation-based lessons impacted positively on the students' learning outcomes and consequently, enhanced their learning.

The analyses of responses given by Learner 3 and Learner 6 in answering the pre- and post- test items for the lesson on Frictional Force confirmed the quantitative results (Figure 1a and Figure 1b; Figure 2a and Figure $\mathbf{2 b}$ for Learner 3 and Learner 6, respectively).

The results from Figure 1a and Figure 2a show that before the simulation-supported lesson on $F F$ was enacted by Teacher A, all the two learners (i.e., Learner 3 and 6) could not answer the question 1(b): "The force that overcomes the opposing force of a body is called...." of the pre-test. It would be envisaged that these learners, as pre-service teachers, would have mastered these concepts by now since, they were expected to teach this same content at the SHS levels in future. However, it appears that Learner 3 had misconstrued Applied Force to mean net force as seen in Figure 1a. An indication that there were gaps in his prior knowledge about Frictional Force. Learner 6 seemed not to have any prior knowledge about it, as he left the space blank. However, after the PhET simulation-supported lesson, they all answered the same question correctly as indicated in Figure $\mathbf{1 b}$ and Figure $\mathbf{2 b}$. These suggest that the intervention helped Learner 3 to clear his misconception about the name of the force that overcomes the 


\section{PHYSICS (SHS 2)}

FRICTIONAL FORCE

Introductory Activity Sheet (Pre-Test)

1. The following questions point out the definition of frictional force. Fill in the blank space with the appropriate term.

(a) The force that must be overcome for a body to move on a rough surface is called frictions!

(b) The force that overcomes the opposing force of a body is called

(a)

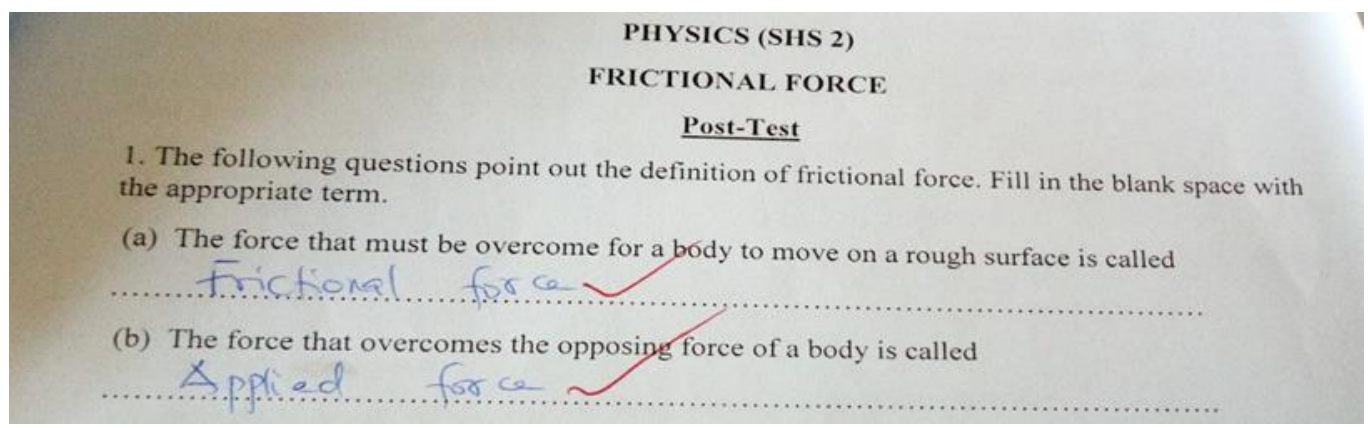

(b)

Figure 2. (a) Excerpt of Learner 6's responses to the pre-test item number 1(b) before the enactment of the SSPL on Frictional Force; (b) Excerpt of Learner 6's responses to the post-test item number 1(b) after the enactment of the SSPL on Frictional Force

opposing (frictional) force. Also, Learner 6's knowledge gaps about Frictional Force were filled. This is an indication (as found with the quantitative results), that the PhET simulation-supported lesson impacted positively on the students' learning outcomes, thus, their learning had been enhanced with the selected simulation environment.

Results from the focus group discussions with the learners after the implementation of the $D O S$ and $F F$ lessons also confirmed this finding. In relation to the $F F$ lesson, learners believed that with the PhET simulation entitled: Force and Motion: Basics (Friction), they learned and understood the concepts under the topic: Frictional Force bettersuggesting that learning was enhanced because their learning outcomes in relation to the topic had improved. The following were the responses gathered from two of the learners in this regard:

Learner 2: ... at first when they teach us, they tell us that for a body to be able to move, the applied force must be greater than the frictional force; that one, it was just an abstract thing, but today with the simulation, it was concrete, we saw clearly that the body was able to move by increasing the applied force [IL].

Learner 7: The use of simulation with respect to the topic selected was appropriate $[A S]$ because today, I got to know that frictional force can also be called retarding force $[I L$ and $C M]$.

Comments as highlighted by the Learner 2 and Learner 7 suggest that the PhETs used in the instructional process was appropriate for learning the $F F$ concept in that, it helped them to clear their misconceptions, enhanced their conceptual understanding and expanded their knowledge of Frictional Force-an indication that their learning enhanced with Force and Motion: Basics (Friction) PhET simulation environment.
Similarly, with the DOS lesson which was taught by Teacher B, the learners believed that their learning had been enhanced because their learning outcomes had improved in relation to the implication of the mathematical expression associated with the physics concept, Hooke's Law which in terms of spring systems; states that "the force needed to extend or compress a spring by some distance is proportional to that distance". Two of the learners explained their improved learning outcomes in this regard as follows:

Learner 1: Considering the mathematical expression of the force, I mean the applied force in relation to the spring constant and then displacement. Initially, I did not find the negative sign so important ..., but later on, I observed from the simulation that the restoring force was acting opposite to the applied force. So, the negative sign is very important. I think I have learnt something new $[I L]$.

Learner 8: ... like as somebody [referring to Learner 1] was saying he now knows the essence of the negative sign; at the SHS, I learned Hooke's Law by "chew and pour" [meaning, rote learning], but then, I did not know the essence of the negative sign until when we started using the simulation here [IL]

The comments by Learner 1 and Learner 8 were confirmed in their respective test papers before and after the enactment of the DOS lesson with the Hooke's Law PhET simulation environment. See Figure 3a and Figure $3 b$; and Figure $4 a$ and Figure $4 b$.

Results from both the focus group discussion data and the answers given by the same learners (i.e., Learner 1 and Learner 8) show that, the SSPL on DOS, helped the learners to make meaning of the negative sign in the Hooke's law mathematical expression. As can be inferred from Figure $3 a$ and Figure $4 a$, both learners omitted the negative sign in 
3. If $\mathrm{K}$ is spring constant, $\mathrm{X}$ is deformation length, and $\mathrm{F}$ is applied force, then Hooke's Law can be written mathematically as. $F=k \times$

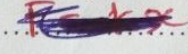

(a)

3. If $\mathrm{K}$ is spring constant, $\mathrm{X}$ is deformation length, and $\mathrm{F}$ is applied force, then Hooke's Law can be written mathematically as . $F=-K X$

(b)

Figure 3. (a) Excerpt of Learner 1's response to pre-test item number 3; (b) Excerpt of Learner 1's response to post-test item number 3

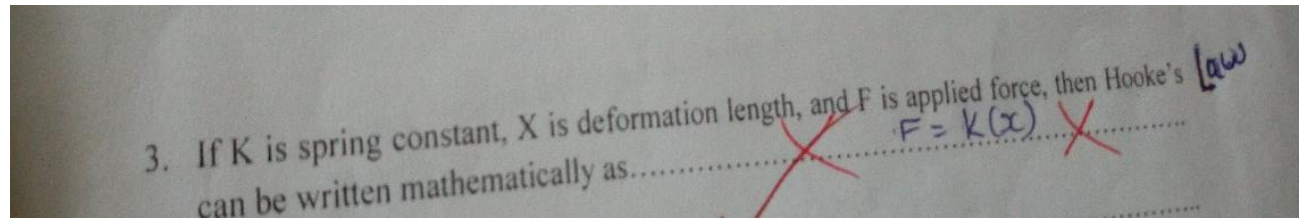

(a)

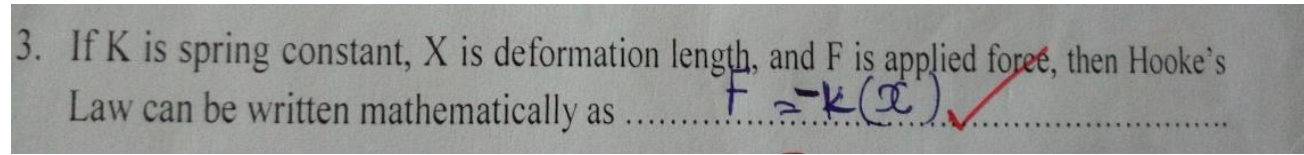

(b)

Figure 4. (a) Excerpt of Learner 8's response to pre-test item number 3; (b) Excerpt of Learner 8's response to post-test item number 3

their mathematical expressions for Hooke's law before the lesson. However, after the lesson with the PhETs, they seemed to have gained deeper conceptual understanding into the subject matter and hence, came to appreciate the essence of the negative sign associated with the mathematical expression for Hooke's law (see Figure $3 \mathbf{b}$ and Figure $4 \mathbf{b}$ ). This suggests that their learning of the subject matter was enhanced with respect to the DOS lesson.

Learners' Perceived Positive Experiences with SimulationSupported Physics Lessons

The results of the study also showed that students' enhanced learning of physics concepts can be explained from the perspective of their perceived positive experiences with the simulation-supported lessons. The survey data on learners' experiences with the SSPLs provided evidence in this regard. Table 4 gives an overview of the learners' scores on the 3 sub-scales after the lessons.

The results indicate that the learners found the lessons very interesting and well understood. In addition, they perceived the presentation of the lessons to be attention grabbing; which promoted class participation. The overall means of the various aspects of the lessons reported by the learners were very high; Interest (Mean $=4.54$, $\mathrm{SD}=0.288)$ followed by Comprehension (Mean $=4.12, \mathrm{SD}=0.490)$, and then Presentation (Mean $=4.08, \mathrm{SD}=0.493$ ). The differences reported between the two lessons for the sub-scales were quite close although sub-scales for lesson on Deformation of Solids were relatively lower in general. In particular, the difference in the Presentation subscale seemed to be more pronounced. The demonstrative form of inquiry adopted by Teacher A for the delivery of the lesson on Deformation of Solids might have contributed to this. Results from the focus group discussions with the learners after the implementation of the DOS lesson also confirmed this finding. Two of the learners
(Learner 4 and Learner 9) after witnessing the DOS lesson by Teacher A had the following to say:

Learner 4: If it is based on my experience with the two lessons, then I will say that the previous lesson [referring to the FF lesson] where we interacted with simulation ourselves was much interesting ... [SI]

Learner 9: This one [referring to the DOS lesson], the teacher demonstrated and he was so fast and since we did not have access to the computer, we could not get the concept ... but with the other lesson [FF lesson], we had access so, even if you missed the concept for the first time, you can always go back to redo. So, I think the first lesson [FF lesson] was more interactive than this [referring to the DOS lesson] because, we were doing and seeing for ourselves [SI, IL]

Comments from the learners seem to suggest that the demonstrative approach in itself as led by the Teacher A was interactive, and that it was the classroom situation adopted where only the teacher had access to the computer (and for that matter, the simulation environment) which posed as a barrier to the instructional process. Apparently, the limited access to computer resources made the DOS lesson which adopted the demonstrative form of inquiry less learner-focused as compared to the $F F$ lesson which was exploratory in nature; wherein learners had access to the computers and so, could explore the simulation environment by themselves.

In all, both qualitative and quantitative results presented pertaining to the research question suggest that the PhETs facilitated enhanced learning of the two selected concepts (i.e., $D O S$ and $F F$ ) in physics based 
Table 4. Learners' scores on the three sub-scales of the lessons

\begin{tabular}{|c|c|c|c|c|c|c|}
\hline & \multicolumn{2}{|c|}{ Deformation of Solids $(\mathrm{N}=9)$} & \multicolumn{2}{|c|}{ Frictional Force $(\mathrm{N}=9)$} & \multicolumn{2}{|c|}{ Overall $(\mathrm{N}=9)$} \\
\hline Subscale & Mean & SD & Mean & SD & Mean & SD \\
\hline Interest & 4.50 & 0.280 & 4.58 & 0.306 & 4.54 & 0.288 \\
\hline Comprehension & 4.06 & 0.507 & 4.20 & 0.491 & 4.12 & 0.490 \\
\hline Presentation & 3.81 & 0.512 & 4.36 & 0.283 & 4.08 & 0.493 \\
\hline
\end{tabular}

on their improved learning outcomes and perceived positive experiences with the SSPLs.

\section{DISCUSSION}

The study explored the affordances of PhET simulations with the goal to provide understanding into how enhanced learning using simulations can be realized through implementation processes. The analysis (from both qualitative evidence; see Figures 1a, 1b, 2a, 2b, 3a, $3 \mathrm{~b}, 4 \mathrm{a}$, and $4 \mathrm{~b}$ and qualitative evidence; see Table 3 and Table 4) showed that the learners' learning of physics concepts was enhanced because of their improved learning outcomes and perceived positive experiences with the PhET simulation-supported lessons. The PhETs' use in the teaching and learning process facilitated enhancements in the learners' understanding of concepts under the topics: Frictional Force and Deformation of Solids. Learners' misconceptions about the subject matter were cleared (see Figures 1a and $\mathbf{1 b}$ ) and also, the formation of their own personal meanings of the concepts under study were advanced. These findings seem to hint that the affordances of the PhETs promoted learners' conceptual change as well as conceptual development of the subject matter-an indication of the extent to which the PhETs facilitated understanding of the physics concepts taught. This explanation is consistent with findings from previous studies (Barak \& Dori, 2005; Bell \& Smetana, 2008; Dega et al., 2013; Jimoyiannis \& Kosmis, 2001; Hannel \& Cuevas, 2018; El Kharki et al., 2020; Ouahi et al., 2021; Pucholt, 2021; Trundle \& Bell, 2005). Specifically, findings in these studies situate computer simulations as useful tools for the enhancement of students' conceptual understanding of concepts in physics.

Also, from the learners' perspective, learning was enhanced because the simulation-supported lessons were interesting, clear, well understood and attention-grabbing (see Table 4). This suggests that the PhET simulation environments shaped learners' learning of the selected concepts for the better by motivating their interest in the subject matter, facilitating their understanding of the concepts studied and engaging their attention throughout the instructional discourse (Chatzopoulos et al., 2021; Fan et al., 2018; Nadiradze et al., 2020; Vlachopoulos \& Makri, 2017; Wieman et al., 2010).

Enhanced learning as observed (based on the high means reported in Table 4 for various aspect of the lessons) could also be attributed to the interactive nature of the exploratory and demonstrative modes of delivery adopted for implementing the lessons. Apparently, these modes of delivery with the PhETs provided the learners with an authentic learning platform for knowledge construction (Agyei et al., 2019; Pucholt, 2021; Sar1 et al., 2017) of the underlying physics concepts whereby their personal experiences were linked to real-world. This is consistent with Wieman et al.'s (2010) observation that PhET simulations afford interactive platforms that engage students to learn through exploration and discovery with the goal to help students to connect real-life phenomena to the underlying subject matter in a particular science (Finkelstein et al., 2006).

Although, the overall results situate the interactive nature of the exploratory and demonstrative modes of delivery adopted for the implementation process as key to learners' enhanced learning outcomes, the demonstration mode of delivery in the context of the study seemed to have been less learner-focused because only the teacher had access to the computer. This explains the pronounced difference in means reported in the Presentation sub-scale for the two lessons (3.81 for $D O S$ and 4.36 for $F F$ ). Apparently, with the DOS lesson, the teacher did most of the demonstration during the implementation process and consequently, learners were limited in learning with the PhETs, as they were not afforded the space to explore the DOS concept adequately with the multiple representation feature of the Hooke's Law simulation environment (Agyei, 2021; Podolefsky, 2010).

\section{RESEARCH LIMITATIONS AND FUTURE WORK}

This study was not without limitations. The fact that data were collected from only nine pre-service physics teachers within a science teacher education programme at the University of Cape Coast limits the findings of the study for broad generalization.

Again, since the study explored the potentials of simulations for enhanced learning in physics classrooms, it would be expected that actual SHS science students-who are the beneficiaries of such ICTbased intervention, would be employed as learners in conducting the study and not pre-service teachers. This perhaps would have brought about deeper insights into the realities of learning with technology in science classrooms at the senior high school. Further research is therefore recommended to examine the extent to which simulations enhance students' learning of physics concepts in the actual high school physics classrooms.

\section{IMPLICATION OF THE STUDY}

It is crucial to stress that even though the results that emanated from this study do not allow for broad generalizations due to the limited scope and specific context, we are of the view that they provide information about the extent to which potentials of simulations promote enhanced learning of high school physics through implementation processes that are sensitive to the Ghanaian context and also, conform to exploratory self-directed and demonstrative forms of inquiry. In the light of this, the following propositions are encouraged for effective use of simulations in physics classrooms for enhanced learning outcomes:

- As the teaching and learning processes with ICT (simulations) strive on availability and access to technological resources, there is need to improve access to ICT resources in Ghanaian SHS classrooms in 
order to ensure that teaching with ICTs is effective in yielding the desired learning outcomes.

- Both exploratory self-directed and the demonstrative forms of inquiry employed for the implementation of the simulation-supported lessons were found in this study to be useful, purposeful, and interactive. However, these modes of delivery were also found to be context-specific. The study therefore recommends that teachers should take the necessary precautions in assessing the resources available in their contexts in any attempt to incorporate simulations in their instructional discourse. In cases, where there are limited computer resources, as typical of most developing countries (e.g., Ghana), the demonstrative form of inquiry is recommended as it provides an affordable and interactive platform for enhanced learning in situations where only the teacher has access to a computer.

\section{CONCLUSION}

The present study was purposed to provide explanations on how enhanced students' learning of physics concepts using simulations through implementation processes are possible. Findings herein support the argument that simulations are useful instructional ICT tool for enabling content development and conceptual change as well as stimulating students' interest in physics as a science subject. In the context of the study, these affordances which were specific to PhET simulations provided the basis for understanding why enhanced learning was observed, as was reflected in the learners' improved learning outcomes and perceived positive experiences with the simulation-supported physics lessons. Central to these findings herein is the interactive and learner-focused nature of the modes of delivery adopted for the implementation of the simulation-supported lessons. The study, therefore, advocates that enhanced learning of concepts in physics with simulations are possible through implementation processes that are exploratory and demonstrative in nature, and context-sensitive.

Author contributions: All authors were involved in concept, design, collection of data, interpretation, writing, and critically revising the article. All authors approve final version of the article.

Funding: The authors received no financial support for the research and/or authorship of this article.

Declaration of interest: Authors declare no competing interest.

Data availability: Data generated or analysed during this study are available from the authors on request.

\section{REFERENCES}

Agyei, D. D. (2012). Preparation of pre-service teachers in Ghana to integrate information and communication technology in teaching mathematics. Universiteit Twente. https://doi.org/10.3990/1.9789036533690

Agyei, D. D. (2021). Integrating ICT into schools in Sub-Saharan Africa: From teachers' capacity building to classroom implementation. Education and Information Technologies, 26, 125-144. https://doi.org/10.1007/s10639-020-10253-w

Agyei, E. D., \& Agyei, D. D. (2019). Feasibility of ICT use in teaching physics in the senior high schools in Ghana. International Journal of Education, Learning and Development, 7(8), 26-41.
Agyei, E. D., Jita, T., \& Jita, L. C. (2019). Examining the effectiveness of simulation-based lessons in improving high school physics teaching: Ghanaian pre-service teachers' experiences. Journal of Baltic Science Education, 18(6), 818-832. https://doi.org/10.33225/jbse/19.18.816

Allan, M. K. (2007). Millennial teachers: Student teachers as users of information and communication - A New Zealand case study International Journal of Education and Development using Information and Communication Technology, 3(2), 16-29.

Azure, J. A. (2015). Senior high school students' views on the teaching of integrated science in Ghana. Journal of Science Education and Research, 1(2), 49-61.

Barak, M., \& Dori, Y. J. (2005). Enhancing undergraduate students through project-based learning in an IT environment. Science Education, 89(1), 117-139. https://doi.org/10.1002/sce.20027

Behar, M., \& Polat, P. (2007). The science topics perceived difficult by pupils of primary 6-8 classes. Diagnosing the problems and remedy solutions. Educational Sciences: Theory and Practice, 7(3), 1113-1130.

Bell, R. L., \& Smetana, L. K. (2008). Using computer simulations to enhance science teaching and learning. In R. L. Bell, J. GessNewsome, \& J. Luft (Eds.), Technology in the secondary science classroom (pp. 23-32). National Science Teachers Association Press.

Buabeng, I., Ampiah, J. G., \& Quarcoo-Nelson, R. (2012). Senior high school female students' interest in physics as a course of study at the university level in Ghana. IFE PsychologIA, 20(1), 369-379.

Chatzopoulos, A., Kalogiannakis, M., Papadakis, S., Papoutsidakis, M., Elza, D., \& Psycharis, S. (2021). DuBot: An open-source, low-cost robot for STEM and educational robotics. In Handbook of Research on Using Educational Robotics to Facilitate Student Learning (pp. 441465). IGI Global. https://doi.org/10.4018/978-1-7998-67173.ch018

Clark, R. C., \& Mayer, R. E. (2003). E-learning and the science of instruction: Proven guidelines for consumers and designers of multimedia Learning. Pfeiffer Publishing. https://doi.org/10.1002/pfi. 4930420510

Cohen, J. (1988). Statistical power analysis for the behavioral sciences (2nd Ed.). Lawrence Erlbaum Associates.

Dega, B. G., Kriek, J., \& Mogese, T. F. (2013). Students' conceptual change in Electricity and Magnetism using simulations: A Comparison of cognitive perturbation and cognitive conflict. Journal of Research in Science Teaching, 50(6), 677-698. https://doi.org/10.1002/tea.21096

Donnellan, C. (2003). Does sex make a difference? An equalities peak for young people on international women's day. The Gender Issues, 64, 14-17.

El Kharki K., Bensamka F., \& Berrada K. (2020). Enhancing practical work in physics using virtual Javascript simulation and LMS Platform. In D. Burgos (Ed.), Radical solutions and e-learning. Lecture Notes in Educational Technology. Springer, Singapore. https://doi.org/10.1007/978-981-15-4952-6_9

Esquembre, F. (2001). Computers in physics education. Computer Physics Communications, 1-6. https://doi.org/10.1016/S00104655(02)00197-2 
Fan, X., Geelan, D., \& Gillies, R., (2018). Evaluating a novel instructional sequence for conceptual change in physics using interactive simulations. Education Sciences, 8(1), 29 https://doi.org/10.3390/educsci8010029

Finkelstein, N. D., Adams, W. K., Keller, C. J., Kohl, P. B., Perkins, K. K., Podolefsky, N.S., Reid, S., \& LeMaster, R. (2005). When learning about the real world is better done virtually: A study of substituting computer simulations for laboratory equipment. Physical Review Special Topics - Physics Education Research, 1(1), 010103. https://doi.org/10.1103/PhysRevSTPER.1.010103

Finkelstein, N., Adams, W., Keller, C., Perkins, K., Wieman, C., \& the Physics Education Technology Project Team. (2006). High-tech tools for teaching physics: The physics education technology project. Journal of Online Learning and Teaching, 2(3), 110-121.

Fu, J. S. (2013). ICT in Education: A critical literature review and its implication. International Journal of Education and Development using Information and Communication Technology, 9(1), 112-125.

Gray, K. E., Adams, W. K., Wieman, C. E., \& Perkins, K. K. (2008). Students know what physicists believe, but they don't agree: A study using the CLASS survey. Physics Education Research, 4(2), 110. https://doi.org/10.1103/PhysRevSTPER.4.020106

Hannel, S. L., \& Cuevas, J. (2018). A study on science achievement and motivation using computer-based simulations compared to traditional hands-on manipulation. Georgia Educational Researcher, 15(1), 3. https://doi.org/10.20429/ger.2018.15103

Jimoyiannis, A., \& Komis, V. (2001). Computer simulations in physics teaching and learning: A case study on students' understanding of trajectory motion. Computers \& Education, 36(2), 183-204. https://doi.org/10.1016/S0360-1315(00)00059-2

Koh, J. H. L. (2013). A rubric for assessing teachers' lesson activities with respect to TPACK for meaningful learning with ICT. Australasian Journal of Educational Technology, 29(6), 887-900. https://doi.org/10.14742/ajet.228

Kohnle, A. (2014). Interactive simulations for the learning and teaching of quantum mechanics concepts. In S. Dormido \& L. de la Torre (Eds.), MPTL'18 - Book of Proceedings: 18th Edition of the Multimedia in Physics Teaching and Learning Conference. European Physical Society, Multimedia in Physics Teaching and Learning Conference, Madrid, Spain.

Kothari, C. R. (2004). Research methodology: Methods \& techniques (2nd ed.). New Age International (P) Limited Publishers.

Martin, R., Sexton, C., \& Gerlovich, J. (2002). Teaching science for all children: Methods for constructing understanding. Allyn and Bacon.

Mbodila, M., Jones, T., \& Muhandji, K. (2013). Integration of ICT in Education: Key challenges. International Journal of Emerging Technology and Advance Engineering, 3(11), 515-520.

Miles, M., \& Huberman, M. (1994). Qualitative data analysis. Sage.

Nadiradze, L., Kapanadze, M., \& Kvirkvelia, B. (2020). Use of technologies, as the effective instrument for enhancing of motivation in the process of physics teaching. INTED2020 Proceedings, 14th International Technology, Education and Development Conference, Spain, 2768-2773. https://doi.org/10.21125/ inted.2020.0828
Ouahi, M. B., Hou, M. A., Bliya, A., Hassouni, T., \& Al Ibrahm, E. M. (2021). The effect of using computer simulation on students' performance in teaching and learning physics: Are there any gender and area gaps? Educational Research International, 2021, 1-10. https://doi.org/10.1155/2021/6646017

Podolefsky N. S., Perkins K. K., \& Adams W. K. (2010). Factors promoting engaged exploration with computer simulations. Physical Review Special Topics - Physics Education Research, 6(2), 020117. https://doi.org/10.1103/PhysRevSTPER.6.020117

Pucholt, Z. (2021). Effectiveness of simulations versus traditional approach in teaching physics. European Journal of Physics, 42(1). https://doi.org/10.1088/1361-6404/abb4ba

Sarı, U., Hassan, A. H., Güven, K., \& Şen, Ö. F. (2017). Effects of the 5E teaching model using interactive simulation on achievement and attitude in physics education. International Journal of Innovation in Science and Mathematics Education, 25(3), 20-35.

Stieff, M., \& Wilensky, U. (2003). Connected chemistry-incorporating interactive simulations into the chemistry classroom. Journal of Science Education and Technology, 12, 280-302. https://doi.org/10.1023/A:1025085023936

Taale, K. D. (2011). Improving physics problem solving skills of students of Somanya Senior High Secondary Technical School in the Yilo Krobo District of Eastern Region of Ghana. Journal of Education and Practice, 2(6), 8-21.

Thompson, F., \& Logue, S. (2006). An exploration of common student misconceptions in science. International Education Journal, 7(4), 553 559.

Trundle, K. C. \& Bell, R. L. (2005). The use of a computer simulation to promote scientific conceptions of moon phases [Paper presentation]. Annual Meeting of the National Association for Research in Science Teaching, Dallas, TX.

Vlachopoulos, D., \& Makri, A. (2017). The effect of games and simulations on higher education: A systematic literature review. International Journal of Educational Technology in Higher Education, 14(22), 1-33. https://doi.org/10.1186/s41239-017-0062-1

Wieman, C. E., Adams, W. K., Loeblein, P., \& Perkins, K.K. (2010). Teaching physics using PhET simulations. The Physics Teacher, 48(4), 225-227. https://doi.org/10.1119/1.3361987

Yin, R. K. (2003). Applications of case study research: Applied social research methods (4th ed.). Sage Publications.

Zacharia, Z. C. (2007). Comparing and combining real and virtual experimentation: An effort to enhance students' conceptual understanding of electric circuits. Journal of Computer Assisted Learning, 23, 120-132. https://doi.org/10.1111/j.13652729.2006.00215.x

Zacharia, Z. C., \& Anderson, O. R. (2003). The effects of an interactive computer-based simulation prior to performing a laboratory inquiry-based experiment on students' conceptual understanding of physics. American Journal of Physics, 71, 618-629. https://doi.org/10.1119/1.1566427 